\title{
ANALYSIS OF DELAY FACTORS IN THE ADVANCED CONSTRUCTION PROJECT COMPLETION OF THE KAUBUN IRRIGATION NETWORK OF 400 HECTARES IN 2014
}

\author{
Gazali Achmad*, Researher \\ Azis Subandiyah, Lecturer \\ National Institute of Technology, Malang, East Java, Indonesia \\ ${ }^{*}$ E-mail: virahulrah44@yahoo.co.id \\ ORCID: 0000-0002-6579-4097
}

\begin{abstract}
This research is conducted to determine the delay factors in time and cost in the advanced construction project in the Kaubun irrigation network of East Borneo, to determine the effect of the most dominant factor, and to determine strategies that can be used by contractors to deal with these factors. Data analysis methods are not used in descriptive statistical, factorial analysis, and path analysis research. However, questionnaires are distributed to 43 respondents. They include the contractors, owners and supervisory consultants involved in the advanced construction project in the Kaubun irrigation network of East Borneo that had delays in time and cost target in the fiscal year of 2014. Based on research findings, significant factors affecting the delays in time and cost in the advanced construction project in the Kaubun irrigation network of East Borneo include: Human Resources factors with a standard $\beta$ coefficient of 0.342 ; Material factor 0.326 , Equipment factor 0.287 , Work Environment factor 0.260 ; and Time Target factor 0.580 . All independent variables do not have an indirect effect on the dependent variable (Y2) of Cost Target. The most dominant factor affecting the delay in time and cost target is Human Resources factor with a standard $\beta$ coefficient of 0.342 . The most dominant factor affecting the cost is the time target with a standard $\beta$ coefficient of 0.580 . A proposed strategy to regulate the delay in time and cost target in the advanced construction project in the Kaubun irrigation network of East Borneo is to recruit professional resources from outside East Borneo including Bali and Java because of competition and experience in demanding maximum work performance. Thus, contractors must prepare human resources with high skills and productivity and prepare foremen who have experience and are educated in the field of supervision in project implementation.
\end{abstract}

\section{KEY WORDS}

Cost, delay factor, construction project, public service.

The construction project in the Kaubun irrigation area (3,600 ha) in East Kutai Regency began to be built in the fiscal year of 2006. It was carried out to support the mission of stabilizing national rice self-sufficiency, especially for local consumption needs, offsetting the increase in East Borneo population, supporting government efforts to improve welfare farmers, creating jobs, improving environmental quality, especially in rural areas, and alleviating poverty. With the development of the Kaubun irrigation network, it can later increase agricultural production, especially rice and secondary crops, turn the non-technical irrigation into technical irrigation networks. Thus, food self-sufficiency can be improved; especially, in Bumi Etam Village, Bumi Rapak Village, and Bumi Jaya Village of Kaubun District of East Kutai Regency in general. Therefore, the improvement in the function and condition of existing irrigation networks is carried out in an area of 400 ha. Three target constraints which include cost, quality, and time of submission have very specific correlation with one another. All three become balancing parameters for achieving goals and objectives even though they are not far from delays (Malik, 2009). Effectiveness is the level of success in facing obstacles to delay in achieving goals (time, cost, quality) (Azis, 2018). While efficiency is the success in maximizing the achievement of goals by using economical resources as possible (Malik, 2009). Assaf et. al., (1995) in their research entitled "Causes of Delay in Large Building Construction Project" stated that the causes of delay could be seen 
in terms of material, labor, equipment, cost, changes in design, scheduling, planning and control, relations with relevant agencies, slow monitoring and testing procedures, environment, contract issues, and the absence of professional consultants and managers. Research Problems:

- What factors affect the delay of contract time in the advanced construction project in the Kaubun irrigation network $(400 \mathrm{Ha})$ ?

- What is the most dominant factor affecting the delay of contract time in the advanced construction project in the Kaubun irrigation network $(400 \mathrm{Ha})$ ?

- What strategies should be conducted to deal with these dominant factors? Research Objectives:

- To analyze factors affecting the delay of contract time in the advanced construction project in the Kaubun irrigation network $(400 \mathrm{Ha})$;

- To analyze the most dominant factor affecting the delay of contract time in the advanced construction project in the Kaubun irrigation network $(400 \mathrm{Ha})$;

- To determine strategies that should be conducted to deal with these dominant factors.

\section{METHODS OF RESEARCH}

Based on the method, this is a descriptive research that aimed to determine the factors affecting the delay of contract time in the advanced construction project in the Kaubun irrigation network of East Borneo. The data collection is conducted using the questionnaire method. The final objective of this research is to determine the factors affecting the delay of contract time in the advanced construction project in the Kaubun irrigation network of East Borneo and the strategies that must be conducted to deal with it.

This research uses a survey method by collecting respondent opinions, experiences and attitudes regarding the problems that have been experienced in the advanced construction project in the Kaubun irrigation network of East Borneo by taking primary data through questionnaires and secondary data from related institutions (Belson, 1986; Lucas, 1974). Based on the factors affecting the delay of contract time, it is continued by determining the variables to be used as the questions to be measured in the form of a questionnaire.

Population and Sample. The research population is the owner, contractor and supervisor consultant who know the conditions and work or are directly involved in the advanced construction project in the Kaubun irrigation network of East Borneo in the fiscal year of 2014. It is 1 work package that experienced a delay in contract time and is carried out by: (1) Owners of 6 people consisting of Work Unit of 2 people, Commitment Making Officials of 2 people and Field Supervisors of 2 people, (2) Contractors of 42 people consisting of Head of Project of 1 person, Engineer of 2 people, Field Person of 1 person, Handymen of 10 people, Foremen of 5 people, and Workers of 32 people. In this research, the samples are taken randomly using disproportionate stratified random sampling (Sugiyono, 2010; Csikszentmihalyi, M., \& Larson, 2014). Based on the results of calculations, the total number of samples to be taken is 43 respondents.

Research Variables. The research variables include the independent variables (X) which consists of: Human Resources (X1), Job Scheduling Methods (X2), Design Changes (X3), Equipment (X4), Work Environment (X5), Materials (X6) and Finance (X7) and the dependent variable $(\mathrm{Y})$, namely the Delay of Contract Time. To obtain the data through a questionnaire, questions are arranged and linked to these variables with their respective indicators.

Data Collection. Data collection was carried out through a questionnaire containing statement items relating to the factors affecting the delay of contract time in the advanced construction project in the Kaubun irrigation network of East Borneo. To find out the most dominant influential factors, the Likert scale is used with a range of 1 to 4 (strongly disagree strongly agree), to avoid the middle score (doubtful) that is difficult to interpret between 
agreeing and disagreeing. So, it is possible to get firmness from the respondents in answering questions from the questionnaire (Brown, 2011). The items in the research variable are designed with positive questions, so that number one is a very negative response code to respond one of the questions, while number four is a very positive response code to respond one of the questions.

\section{RESULTS AND DISCUSSION}

Strategies to Deal with the Delay in Target Time and Cost. Based on the results of path analysis on model 1, Human Resource Factor (X2), Material Factor (X3), Equipment Factor (X4), and Work Environment Factor (X7) are factors that significantly affect the Time Target (Y1) and the most dominant factor is Human Resources (X2). It means that the higher the HR value, the faster the project will be completed. Therefore, for construction project implementers, HR factors should get considerable attention so as to shorten project completion. Meanwhile, the factors that have no significant effect are Financial Factor, Work Implementation Method Factor (X5) and Changes in Design Factor (X6).

Table 1 - Sequence of the Summary of Path Analysis Results

\begin{tabular}{|c|c|c|}
\hline Rank & Variables & Standardized Coefficient $\beta$ \\
\hline 1 & Human Resources (X2) & 0.342 \\
\hline 2 & Material (X3) & 0.326 \\
\hline 3 & Equipment (X4) & 0.287 \\
\hline 4 & Work Environment (X7) & 0.260 \\
\hline 5 & Finance (X1) & -0.222 \\
\hline 6 & Changes in Design (X6) & 0.033 \\
\hline 7 & Implementation Method (X5) & -0.009 \\
\hline
\end{tabular}

Based on path analysis on model 2 in Table 1 (4.24), Time Target (Y1), Human Resource Factor (X2), Material Factor (X3), Equipment Factor (X4), Changes in Design Factor (X6) and Work Environment Factor (X7) are the factors that significantly affect Cost Target (Y2) and the most dominant variable is the Time Target Variable (Y1). Therefore, for construction project implementers, besides paying attention to HR factors, it should also pay attention to the time target so that the project can be completed quickly and does not require a lot of money. Meanwhile, the factors that have no significant effect are Finance Factor and Work Implementation Method Factor. Furthermore, the factors that affect the delay in time and cost can be explained as follows:

- Human Resource Factor (X2), which is the result of reduction of manifest variables consisting of: availability of human resources (X2.1), skills and productivity of labor (X2.2) and HR responsibility (X2.4);

- Material Factor (X3), which is the result of reduction of manifest variables consisting of: material deficiency (X3.1), material damage and change (X3.2), late material delivery (X3.3), material scarcity in warehouse (X3.4) and deviations use of materials from specifications (X3.5);

- Equipment Factor (X4), which is the result of reduction of manifest variables consisting of: delay in equipment delivery (X4.6), lack of equipment (X4.7), is Damage to the existing equipment $(X 4.8)$ and problem of heavy equipment in reaching the project site (X4.9);

- Changes in Design Factor (X6), which is the result of reduction of manifest variables consisting of: frequent changes in design by the owner (X6.1), delay in the process of change from planning $(X 6.2)$ and failure of initial planning and changes that has been designed by owner > 10\% (X6.3);

- Work Environment Factor (X7), which is the result of a reduction of manifest variables consisting of: topographic state (X7.4), the effect of culture (X7.5), narrow working conditions (X7.6) and air temperature (X7.7); 
- Target Time (Y1), which is the result of a reduction of manifest variables consisting of: not proportional time to the volume (Y1.1), waiting for the test results by the owner (Y1.2) and the setback of work implementation (Y1.3).

Strategies Used for Human Resources Factor on Time and Cost Target:

Table 2 - Sequence of Summary of Path Analysis Results

\begin{tabular}{|c|c|c|}
\hline Rank & Variables & Standardized Coefficient $\beta$ \\
\hline 1 & Time Target (Y1) & 0.580 \\
\hline 2 & Work Environment $(\mathrm{X} 7)$ & 0.497 \\
\hline 3 & Material (X3) & 0.488 \\
\hline 4 & Equipment $(\mathrm{X} 4)$ & 0.376 \\
\hline 5 & Changes in Design (X6) & -0.361 \\
\hline 6 & Human Resources (X2) & 0.315 \\
\hline 7 & Implementation Method (X5) & 0.251 \\
\hline 8 & Finance (X1) & -0.137 \\
\hline
\end{tabular}

Based on Table 2, the Time Target variable is the variable that has the greatest path coefficient. It means that the Cost Target variable is most influenced by the Time Target variable. A positive path coefficient indicates that the faster the time, the less the cost is needed. Based on Table 1 and 2 Human Resources factor is the variable that has the first largest standardized $\beta$ coefficient value against the target time and the sixth largest standardized $\beta$ coefficient value on the cost target. So, in this research, the delay factor in time and cost in the advanced construction project in the Kaubun irrigation network of East Borneo is human resource factor. In other words, the delay factors in time and cost in the advanced construction project in the Kaubun irrigation network of East Borneo is strongly affected by human resource factor. Then, the most influential indicators of the delay in the time and cost target of the human resource factor can be seen in the high communality values in Table 3 as follows:

Table 3 - Communality Values of Human Resource Factor

\begin{tabular}{|c|l|c|}
\hline Manifest Variables & \multicolumn{1}{|c|}{ Description } & Communality Values \\
\hline X2.2 & Labor skills and productivity & 0.612 \\
\hline X2.4 & Big HR responsibility & 0.582 \\
\hline X2.1 & Availability of human resources & 0.380 \\
\hline
\end{tabular}

Based on Table 3, on the human resource factor, the indicator that most affects the delay in time and cost target is labor skills and productivity (X2.2) with a communality value of 0.612 . So, the strategy used is to provide human resources that have high skills and productivity and have responsibilities in completing work. If local resource is not available, then the human resources must be collected from outside East Kalimantan, for example the Bali or Java islands, in accordance with the competencies and experience to support the needs of work implementation.

Strategies Used for Material Factor on Time and Cost Target. Based on Tables 1-2, Material Factor is the variable that has the second largest standardized $\beta$ Coefficient value on the time target and the third largest standardized $\beta$ Coefficient value on the cost target. It means that the delay in time and cost target in the advanced construction project in the Kaubun irrigation network of East Borneo is also significantly affected by material factor. Then, indicators that have the most effect on the delay in the time and cost target of material factor can be seen in the high communality values in Table 4 as follows:

Table 4 - Communality Values of Material Factor

\begin{tabular}{|c|l|c|}
\hline Manifest Variables & \multicolumn{1}{|c|}{ Description } & Communality Values \\
\hline X3.3 & Late material delivery & 0.653 \\
\hline X3.4 & Scarcity of material in warehouse & 0.541 \\
\hline X3.2 & Material damage and changes & 0.522 \\
\hline X3.5 & Deviations Use of materials from specifications & 0.521 \\
\hline X3.1 & Lack of material & 0.264 \\
\hline
\end{tabular}


Based on Table 4, from material factors, the indicator that most affects the delay in the time and cost target is late material delivery (X3.3) with a communality value of 0.653 , then the strategy used is that the contractor must immediately collect the material, especially local and non-local materials to the project site. In addition, the contractor must take into account the use of materials in the field and prepare material supplies in the warehouse. Then, the contractor must take samples and check the quality of the materials sent to the work site. In addition, if it is difficult to collect the material at the work site, the contractor must collect it from outside the area.

Strategies Used for Equipment Factor on Time and Cost Target. Based on Tables 1 and 2, Equipment Factor is the variable that has the third largest standardized $\beta$ coefficient value on the time target and the fourth largest standardized $\beta$ coefficient value on the cost target. It means that the delay in time and cost in the advanced construction project in the Kaubun irrigation network of East Borneo is also affected by equipment factor. Then, the most influential indicator of the delay in the time and cost target based on the equipment factor can be seen in the high communality values in Table 5 as follows:

Table 5 - Communality Values of Equipment Factor

\begin{tabular}{|c|l|c|}
\hline Manifest Variables & \multicolumn{1}{|c|}{ Description } & Communality Values \\
\hline X4.7 & Lack of equipment & 0.680 \\
\hline X4.9 & Difficulty for heavy equipment in reaching the project site & 0.591 \\
\hline X4.6 & Late equipment delivery & 0.582 \\
\hline X4.8 & Damage to the existing equipment & 0.500 \\
\hline
\end{tabular}

Based on table 5, the equipment factor that most affects the failure to achieve the time and cost target is the lack of equipment (X4.7) with a communality value of 0.680 . Then, the strategy used to deal with it is that the contractor must own the necessary heavy equipment, bring rental equipment to meet job requirements, provide appropriate equipment (types and quantities) based on the conditions in the field, accelerate mobilization before the starting the work, prepare spare parts for equipment, prepare mechanics for maintenance and repair of equipment.

Strategies Used for Changes in Design Factor on Time and Cost Target. The changes in design factor is a variable that has the fifth largest standardized $\beta$ coefficient value on the cost and time target. It means that the delay in time and cost in the advanced construction project in the Kaubun irrigation network of East Borneo is also affected by changes in design factor. Then, the most influential indicator of the delay in the time and cost target based on the changes in design factor can be seen in the high communality values in Table 6 as follows:

Table 6 - Communality Values of Changes in Design Factor

\begin{tabular}{|c|l|c|}
\hline $\begin{array}{c}\text { Manifest } \\
\text { Variables }\end{array}$ & \multicolumn{1}{|c|}{ Description } & $\begin{array}{c}\text { Communality } \\
\text { Values }\end{array}$ \\
\hline X6.1 & Frequent changes in design by the owner & 0.780 \\
\hline X6.2 & Delay in the process of change from the planning & 0.526 \\
\hline X6.3 & Failed initial planning and changes that have been designed by the owner $>10 \%$ & 0.464 \\
\hline
\end{tabular}

Based on Table 6, from the changes in design factor, the indicator that most affects the delay in the time and cost target is the frequent changes in design by the owner (X6.1) with a communality value of 0.780 . So, the strategy used to deal with it is that the contractor must anticipate the delay in the process of change from planning and design changes made by the owner. The contractor should also immediately submit a Change Order/ Review Design/ Addendum Contract and reschedule after the field engineering is held.

Strategies Used for Work Environment Factor on Time and Cost Target. Based on Tables 1 and 2, the work environment factor is the variable that has the fourth largest standardized $\beta$ coefficient value on the time target and the second largest standardized $\beta$ Coefficient value on the cost target. It means that the delay in time and cost in the advanced construction project in the Kaubun irrigation network of East Borneo is also affected by work 
environment factor. Then, the most influential indicator of the delay in the time and cost target based on the work environment factor can be seen in the high communality values in Table 7 as follows:

Table 7 - Communality Values of Work Environment Factor

\begin{tabular}{|c|c|c|}
\hline Manifest Variables & Description & Communality Values \\
\hline X7.6 & Narrow road at the project site & 0.581 \\
\hline X7.4 & Topography & 0.505 \\
\hline X7.5 & Cultural influences & 0.415 \\
\hline X7.7 & Air temperature & 0.309 \\
\hline
\end{tabular}

Based on Table 7, from work environment factor, the indicator that most affects the delay in the time and cost target is the narrow road at the project site (X7.6) with a communality value of 0.581 . Thus, the strategy used to deal with it is that the contractor must adjust the type and amount of equipment with the work environment, anticipate earlier environmental conditions in connection with the preparation of equipment, materials and labor since the field engineering is carried out, add the number of workers and the number of working hours (overtime) at night to replace the lost working days, and use labor from outside the area.

Strategies Used for Time Target Factor on Cost Target. Time target on delay in cost target in the advanced construction project in the Kaubun irrigation network of East Borneo is also affected by time target factor. Then, the most influential indicator of the delay in time target based on the cost target can be seen in the high communality values in Table 9 as follows:

Table 8 - Communality Values of Time Target Factor

\begin{tabular}{|c|c|c|}
\hline Manifest Variables & Description & Communality Values \\
\hline Y1.2 & Waiting for the test results by the owner & 0.619 \\
\hline Y1.1 & Time is not proportional to volume & 0.475 \\
\hline Y1.2 & Delay in work implementation & 0.407 \\
\hline
\end{tabular}

Based on table 8, from the time target factor, the biggest indicator affecting the failure of the target cost is waiting for the test results by the owner (Y1.2) with a communality value of 0.619. Then, the strategy used to deal with it is the contractor must submit earlier the request for inspection of work items that have been carried out, the contractor must add resources (equipment, labor and materials) and must increase working hours (overtime). The contractor must carry out work according to a predetermined schedule (reschedule).

Summary of the Strategies. The contractor must provide HR that has high skills and productivity and has responsibility in completing work. If local human resource is not available, then it must bring in the human resources from outside East Borneo, for example Bali or Java Islands in accordance with the needs of competence and experience in carrying out work.

The contractor must immediately get the material, especially local and non-local materials to the project site, the contractor calculates the use of materials in the field and prepares supplies of materials in the warehouse, takes samples and checks the quality of the materials sent to work sites. In addition, if it is difficult to get material on the job site, the contractor must collect it from outside the area.

The contractor must own heavy equipment and rent equipment to meet work requirements, provide appropriate equipment (types and quantities) with conditions in the field, accelerate mobilization before starting the work, prepare spare parts for equipment, and prepare mechanics for maintenance and repair of equipment.

The contractor must adjust the type and amount of equipment with the work environment, anticipate earlier environmental conditions in connection with the preparation of equipment, materials and labor since field engineering is carried out, add the number of 
workers and the number of working hours (overtime) at night to replace the lost workdays, and use labor from outside the area.

Summary of Strategies to Deal with the Delay in Cost Target. The contractor must anticipate the delay in the process of change from planning and design changes made by the owner. The contractor should also immediately submit a Change Order/ Review Design/ Addendum Contract and reschedule after the field engineering is held.

The contractor must submit earlier the request for inspection of work items that have been carried out, the contractor must add resources (equipment, labor and materials) and must increase working hours (overtime). The contractor must carry out work according to a predetermined schedule (reschedule).

\section{CONCLUSION}

The factors that significantly affect the delay in the target time in the advanced construction project in the Kaubun irrigation network of East Borneo (400 Ha) are HR Factor with the Standardized coefficient value 4.832, Material Factor of 4.333, Equipment Factor of 3.698, and Work Environment Factor of 2,587. The most dominant factor affecting the delay in the target time in the advanced construction project in the Kaubun irrigation network of East Borneo (400 Ha) is the HR Factor with the Standardized $\beta$ value of 0.342 . Meanwhile, the most dominant factor affecting the delay in cost target in the advanced construction project in the Kaubun irrigation network of East Borneo (400 Ha) is the Time Target Factor with the Standardized $\beta$ value of 0.580 .

The strategy to deal with the delay in time target is providing HR that has high skills and productivity and has responsibility in completing work. If local human resource is not available, then it must bring in the human resources from outside East Borneo, for example Bali or Java Islands in accordance with the needs of competence and experience in carrying out work. In addition, in terms of cost target, the contractor must submit earlier the request for inspection of work items that have been carried out, the contractor must add resources (equipment, labor and materials) and must increase working hours (overtime). The contractor must immediately get the material, especially local and non-local materials to the project site, calculate the use of materials in the field and prepares supplies of materials in the warehouse. Moreover, the contractor must own heavy equipment and rent equipment to meet work requirements provide appropriate equipment (types and quantities) with conditions in the field, accelerate mobilization before starting the work, prepare spare parts for equipment, and prepare mechanics for maintenance and repair of equipment.

\section{REFERENCES}

1. Assaf, S. A., Al-Khalil, M., \& Al-Hazmi, M. (1995). Causes of delay in large building construction projects. Journal of management in engineering, 11(2), 45-50.

2. Azis, S. (2018). Efficiency of Irrigation Water Utilization towards Environmental and Sustainable Plant Patterns and Adapted to a Climate Change, International Journal of Civil Engineering and Technology, 9(10), 1371-1381.

3. Belson, W. A. (1986). Validity in survey research: with special reference to the techniques of intensive interviewing and progressive modification for testing and constructing difficult or sensitive measures for use in survey research: a report (Vol. 201). Gower Publishing.

4. Brown, J. D. (2011). Likert items and scales of measurement. Statistics, 15(1), 10-14.

5. Csikszentmihalyi, M. (2014). Validity and reliability of the experience-sampling method. In Flow and the foundations of positive psychology (pp. 35-54). Springer, Dordrecht.

6. Lucas, W. A. (1974). The case survey method: Aggregating case experience. Rand.

7. Malik, A. (2009). Konstruksi Gedung Faktor Penyebab dan Tindakan Pencegahannya." Jurnal Momentum

8. Morris, T., \& Wood, S. (1991). Testing the survey method: continuity and change in British industrial relations. Work, Employment and Society, 5(2), 259-282.

9. Sugiyono. 2010. Metode Penelitian Kuantitatif, Kualitatif, dan R\&D. CV Alfabeta. 